\title{
Sertolizumab Tedavisine Sekonder Demiyelizan Hastalık Geçiren Bir Vaka
}

\author{
A Case of Demyelinating Disease Secondary to Certolizumab Therapy \\ İlhan Yıldırım ${ }^{1}$, Emel Gönülliü${ }^{2}$, Didar Şenocak ${ }^{1}$ \\ ${ }^{1}$ Sakarya Üniversitesi İ̧ Hastalıkları Bölümü \\ ${ }^{2}$ Sakarya Üniversitesi İ̧̧ Hastalıkları Romatoloji Bölümü \\ Yazıșma Adresi / Correspondence: \\ İlhan Yıldırım \\ Sakarya Üniversitesi, İç Hastalıkları Bölümü Sakarya, TÜRKIYE \\ T: +90507 8593430 E-mail: driyldrm@gmail.com
}

Geliş Tarihi / Received : 20.11.2018 Kabul Tarihi / Accepted : 16.11.2019

Orcid:

İlhan Yıldırım https://orcid.org/0000-0003-0600-7249

Emel Gönüllüi https://orcid.org/0000-0002-6990-4206

Didar Şenocak https://orcid.org/0000-0001-9840-9004

Tüm yazarlar çıkar çatışması olmadığını belirtmiştir.

( Sakarya Tip Dergisi / Sakarya Med J 2019, 9(4):698-701 ) DOI: 10.31832/smj.486011

Öz

Anti- tümör nekrotizan faktör alfa inhibitörü ajanları çeșitli otoimmün ve inflamatuvar barsak hastalıklarında alternatif tedavi olarak üretilmiștir. Klinik etkinliklerine rağmen anti-TNFa ajanlarının santral sinir sisteminde demyelinizasyon gibi nörolojik yan etkiler yaptığ literatürde belirtilmiştir. Biz bu makalemizde anti-TNFa ajanların beşincisi olan sertolizumaba bağlı demyelinizasyon gelişen bir vakayı inceledik. 32 yaşında bayan hastanın klinik şikayeti çift ve bulanık görmeydi. Hastaların anti-TNFa ajan kesilip pulse steroid verildikten sonra hastanın șikayetleri geriledi.

Anahtar Sertolizumab, Anti-TNFa ajanları, Demyelinizasyon

kelimeler

Abstract

Anti-TNFa are an established therapeutic option for several autoimmune and inflammatory bowel diseases. Despite their clinical effectiveness, neurological adverse events have been reported and literature data suggest a potential role of anti-TNFa in the induction of demyelination of the central nervous system. In this article, we examined a case of demyelinization due to certolizumab which is the fifth of anti-TNF agents. A 32-year-old female patient presented with complaints as blurred and to see double. After anti-TNFa agent was discontinued and pulse steroid was given, the patient's complaints regressed.

Keywords Certolizumab, Anti-TNFa agents, Demyelination 


\section{GIIRIŞ}

Tümör nekroz faktörü temel olarak monosit, makrofajlar ve T-lenfositlerce üretilen romatoid artrit, ankilozan spondilit, psoriatik artrit, psöriazis, inflamatuvar barsak hastalıkları başta olmak üzere birçok hastalığı patogenezinde önemli rolü olan pleomorfik proinflamatuvar bir sitokindir. ${ }^{1,2}$ Anti-TNFa ajanları romatoid artrit, psöriazis, ankilozan spondilit, inflamatuvar barsak hastalığ $1 \mathrm{vb}$. hastalıklarda büyük başarı oranı, güvenli etkinlik ile devrim yarattı. ${ }^{3,4}$ Ancak her ne kadar güvenli ve etkili bir tedavi olsa da son on beş yılda kullanımlarının artması ile beraber mekanizması tam anlaşılamamış yan etkiler karşımıza çıkmaktadır. ${ }^{3}$ Bunlar ciddi anlamda viral, fungal, bakteriyel enfeksiyonlar için risk oluşturmak ile beraber, hemositopeni, konjestif kalp yetmezliği rapor edilen yan etkilerdendir. ${ }^{3,5,6}$ Ayrıca sayısız nörolojik komplikasyonlara neden olmaktadır ki bunların en yaygın olanı demiyelinizasyon durumunun ortaya çıkması ya da alevlenmesi olarak bildirilmektedir. ${ }^{7-11}$ Ancak anti-TNFa ajanların kullanımı sonucu hastalarda multıpl sklerozu tetiklediğine veya santral sinir sisteminde yeni demiylenizasyonu indüklediğine dair tartışmalar mevcut.

Biz bu makalede anti-TNFa ajanlarından sertolizumab tedavisine bağlı santral sinir sisteminde demiyelinizayon meydana gelen bir vakayı incelemek istedik.

\section{VAKA}

32 yaşında bayan hasta 2013 yılında bel ağrıları ile Sakarya Eğitim Araştırma Hastanesi romatoloji polikliniğgine başvurdu. Yapılan tetkikler sonucu spondiloartropati olarak değerlendirilerek hastaya nonsteroid antiinflamatuvar ilaç ve sulfasalazin tedavisi başlandı. Hastanın mevcut tedavi altında 4 yıl boyunca şikayetleri olmadı. Takiplerinde tekrar şikayetleri başlayan hastaya mevcut tedavinin yetersiz olduğu düşünülerek sertolizumab 200 mg her iki haftada bir uygulanmak üzere başlandı. Tedavinin 7. ayında hasta bulanık, çift görme şikayetleri ile göz hastalıklarına başvurdu. Papil stazı saptanan hasta optik nörit ön tanısı ile nörolojiye sevk edildi. Hastanın nörolojik muayenesinde; 1şık refleksi +/+, sağ gözde içe bakış kısıtlılı̆̆ı (3 mm), göz dibinde sağ temporalde silinme olup sol göz dibi normal, alt ve üst ektremite fleksör ve ekstansör kas kuvveti 5/5, derin tendon refleksleri normal, taban cilt refleksi her iki tarafta fleksör olarak saptandi. Laboratuvar testlerinde tam kan sayımı ve biyokimyasal parametreleri normal, sedimentasyon 1 saat:39 mm/saat, CRP:10 mg/L, Ig G/A/M normal, ANA/ENA profili / dsDNA negatif olarak saptand. Oligoklonal bant ve IgG indeksi negatif saptand. Hastanın çekilen kontrastlı beyin MR'ı T2 sekanslarında "Sağ bulbus yarımında, temporal lobda halo tarzında ve sol ventrikül çevresinde 2 adet halo tarzında kontrast tutan hiperintens lezyon"(Şekil 1) şeklinde raporlanmıştır. Hastanın kontrastlı torakal ve lomber MR normal olarak raporlandı. Sertolizumab sonrası mevcut kliniğin oluşmas1; hastada anti-TNFa ajanlarına sekonder demiyelinizan tablo meydana geldiğini ön planda düşündürdü.
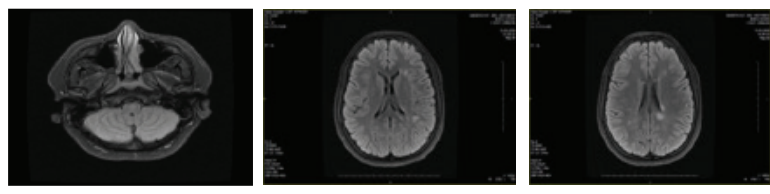

Şekil 1. Sertolizumab kullanımına sekonder santral sinir sisteminde demiyelinizan tutulum görüntüleri

\section{SONUÇ}

Ülkemizde kullanılmakta olan tümör nekrotizan faktör alfa inhibitörü (anti-TNFa) ajanlar ailesine katılan ve grubun beşinci üyesi olan sertolizumab pegol, TNFa' ya karşı oluşturulmuş humanize bir monoklonal antikorun, rekombinan yapıda ve polietilen glikol ile pegilize edilmiş Fab kısmından oluşur. ${ }^{12}$ Sertolizumab öncelikle 2008 yılında Crohn hastalığı için, akabinde 2009 yılında romatoid artrit, 2013 yılında psöriatik artrit ve ankilozan spondilit kullanımı için FDA'den onay almıştır.

Anti-TNFa ajanlarının kullanımına sekonder nörolojik ciddi yan etkiler bildirilmiş olup özellikle demiyelinizasyona neden olan multıpl skleroz, optik nörit, çeşitli periferik nöropatiler (Guillain Barre, kronik inflamatuvar demiyelinizan polinöropati, iletim bozukluğu ile giden 
multifokal polinöropati, aksonal polinöropati) bunların içerisinde bulunmaktadır. ${ }^{13}$ Mevcut rehberler multıple skleroz gibi demiyelinizan tablosu bulunan ya da aile hikayesi olan insanların anti-TNFa ajanların kullanımı sonucu santral sinir sisteminde artmış demiyelinizasyon ile karşı karşıya olduğunu söylemektedir. ${ }^{13}$ Bizim hastamızın özgeçmişinde demiyelinizan bir hastalık öyküsü yoktu. Hastanın özgeçmişinde demyelinizan bir patoloji öyküsü olmasa da mevcut durumun var olan bir demyelinizan hastalığın tetiklenmesi mi yoksa kullanılan ajana sekonder gelişen bir demiyelinizan patoloji mi olduğunun ayrımı yapılamamaktadır. Bu ayrım yapılamasa bile hastada demiyelinizasyon geliştiğinde bundan sonraki basamakta kullanılacak tedavide farklı bir yol izlemek gerekecektir.

Sonuç olarak anti-TNFa ajanlarını kullanan hastalarda santral sinir sisteminde demiyelinizasyon gelişebileceği unutulmamalıdır. 
Sakarya Tip Dergisi 2019;9(4):698-701

\section{Kaynaklar}

1. Feldmann M, Steinman L. Design of effective immunotheraphy for human autoimmunity. Nature 2005;435(7042):612-9.

2. Monaco C, Nanchahal J, Taylor P, Feldmann M. Anti-TNF therapy: past, present and future. Int Immunol 2015;27(1):55-62.

3. Lin J, Ziring D, Desai S, Kim S, Wong M, Korin Y, Braun J, Reed E, Gjertson D, Singh $R R$. "TNF® blockade in human diseases: an overview of efficacy and safety," Clinical Immunology, vol. 126, no. 1, pp. 13-30, 2008

4. M. P. Karampetsou, S. N. C. Liossis, and P. P. Sfikakis, "TNF- $\$ antagonists beyond approved indications: stories of success and prospects for the future," QJM, vol. 103, no. 12, pp. 917-928, 2010

5. K. L. Hyrich, A. J. Silman, K. D. Watson, and D. P. M. Symmons, "Anti-tumour necrosis factor $\otimes$ therapy in rheumatoid arthritis: an update on safety," Annals of the Rheumatic Diseases, vol. 63, no. 12, pp. 1538-1543, 2004.

6. A. T. Borchers, N. Leibushor, G. S. Cheema, S. M. Naguwa, and M. E. Gershwin, "Immune mediated adverse effects of biological used in the treatment of rheumatic diseases," Journal of Autoimmunity, vol. 37, no. 4, pp. 273-288, 2011.

7. van Oosten BW, Barkhof F, Truyen L, Boringa JB, Bertelsmann FW, von Blomberg BM, Woody IN, Hartung HP, Polman CH. "Increased MRI activity and immune activation in two multiple sclerosis patients treated with the monoclonal anti-tumor necrosis factor antibody cA2," Neurology, vol. 47, no. 6, pp. 1531-1534, 1996.
8. The Lenercept Multiple Sclerosis Study Group and The University of British Columbia MS/ MRI Analysis Group, "TNF neutralization in MS: results of a randomized, placebo-controlled multicenter study," Neurology, vol. 53, no. 3, pp. 457-465, 1999.

9. Mohan N, Edwards ET, Cupps TR, Oliverio PJ, Sandberg G, Crayton H, Richert JR, Siegel $J N$. "Demyelination occurring during anti-tumor necrosis factor alpha therapy for inflammatory arthritides," Arthritis \& Rheumatism, vol. 44, no. 12, pp. 2862-2869, 2001.

10. H. J. Freeman and B. Flak, "Demyelination-like syndrome in Crohn's disease after infliximab therapy," Canadian Journal of Gastroenterology, vol. 19, no. 5, pp. 313-316, 2005.

11. M. Tanno, I. Nakamura, S. Kobayashi, K. Kurihara, and K. Ito, "New-onset demyelination induced by infliximab therapy in two rheumatoid arthritis patients," Clinical Rheumatology, vol. 25, no. 6, pp. 929-933, 2006.

12. Neil Weir, Dee Athwal, Derek Brown, Roly Foulkes, George Kollias, Andrew Nesbitt, Andy Popplewell, Mari Spitali, Sue Stephens. A new generation of highaffinity humanized pegylated Fab fragment anti-tumor necrosis factor- $\alpha$ antibodies. Therapy 2006;3:535-45.

13. Kemanetzoglou E, Andreadou E. CNS demyelination with TNF- $\alpha$ blockers. Curr Neurol Neurosci Rep. 2017;17:36. 